\title{
KIT NM_000222.2:c.2537A>G
}

National Cancer Institute

\section{Source}

National Cancer Institute. KIT NM 000222.2:C.2537A>G. NCI Thesaurus. Code C155717.

A nucleotide substitution at position 2537 of the coding sequence of the KIT gene where adenine has been mutated to guanine. 